Corrigendum

\title{
Corrigendum to "Beta version' of neuroplasticity or absolute beta power in preterm infants as electroencephalographic correlate of synaptogenesis" [International Journal of Psychophysiology, Volume 131, Supplement (October 2018), Pages S181-S182]
}

\author{
D. Chegodaev ${ }^{\mathrm{a}}$, O. Lvova ${ }^{\mathrm{a}}$, L. Shalkevich ${ }^{\mathrm{b}}$, P. Pavlova ${ }^{\mathrm{a}}$, N.V. Pavlova ${ }^{\mathrm{a}}$ \\ ${ }^{a}$ Ural Federal University named after the first President of Russia B.N Yeltsin, Yekaterinburg, Russian Federation \\ ${ }^{\mathrm{b}}$ Belarusian Medical Academy of Postgraduate Education, Minsk, Republic of Belarus
}

The authors regret for the below errors in the article:

\section{Introduction}

Electroencephalographic (EEG) power age dynamics largely reflects brain maturation in both term and preterm infants (Jennekens et al., 2012). EEG is widely used for evaluation neurological complications of prematurity. Significant factor for the development of neuropsychological complications in preterm infants is reduced neuroplasticity, particularly, impaired synapses formation (Dean et al., 2014). The participation of networks of GABA-interneurons is necessary to provide synaptogenesis (Oh et al., 1991). This process intensively lasts during early postnatal life. In turn, from electrophysiological point of view, GABA-interneurons are considered as pacemakers of EEG beta-band activity (van Lier et al., 1991).

The aim of this study is to evaluate the difference between EEG beta- 1 power in term and preterm infants. This work supports the hypothesis that total beta-power can serve as relative marker of synaptogenesis during early postnatal brain development.

\section{Methods}

Absolute spectral power of beta-band (13-17 Hz) activity was calculated (FFT, Hanning window) in two age groups of term infants ( $\mathrm{n}=10$ in each) with typical development at 5 months (mean age $(\mathrm{ma})=4.89, \mathrm{SD}=0.46$ ) and 10 months ( $\mathrm{ma}=10,73, \mathrm{SD}=0.21)$ and the same amount of preterm infants $(28-36$ weeks gestational age), without malformations and severe brain lesions in corresponding to the corrected age (ca) groups ( $\mathrm{ca}=5.68$ months, $\mathrm{SD}=0.27$; $\mathrm{ca}=10.16$ months, $\mathrm{SD}=0.65$ ). Both groups matched sex and socioeconomic status. The background EEG activity of awake subjects (relative resting state) was registered with high-density HydroCel Geodesic Sensor Net, Net Amps $300 \mathrm{am}-$ plifier (128 channels) at the sampling rate $1000 \mathrm{~Hz}$ with vertex reference. The collected data were processed with the NetStation 4.6.3 software.

\section{Results}

One-way ANOVA test showed significant difference of absolute spectral power values in beta-1 frequency range between groups only in 5 months $(\mathrm{p}=0,001)$

\section{Conclusions}

Previously it was surprisingly shown increased absolute beta power in preterm infants between 33 and 36 weeks gestation and beta power values peaked in 34 week (Bell et al., 1991). Notably, 34 week gestation is considered to be the age of entry into peak period of synaptogenesis (Tau and Peterson, 1991).

Our study demonstrated that infants born preterm compared with full-term infants show reduced beta power at 5 months age but not at 10 months. Given the absence of essential neurological pathology in preterm infants the data obtained could indicate physiological differences in brain maturation between compared groups. Particularly the received results can correspond to brain synaptogenesis as descending process.

\section{Funding}

This work was supported by a grant of the Russian Science Foundation 16-18-10371

The authors would like to apologise for any inconvenience caused.

DOI of original article: $10.1016 / \mathrm{j} . \mathrm{ijpsycho.2018.07.483}$

\section{References}

Bell, A.H., McClure, B.G., McCullagh, P.J., McClelland, R.J., 1991. Variation in power spectral analysis of the EEG with gestational age. J Clin Neurophysiol. 91 (8), 312-319.

Dean, J.M., Bennet, L., Back, S.A., McClendon, E., Riddle, A., Gunn, A.J., 2014. What brakes the preterm brain? An arresting story. Pediatr Res. 75 (1-2), 227-233.

Jennekens, W., Niemarkt, H.J., Engels, M., Pasman, J.W., van Pul, C., Andriessen, P., 2012. Topography of maturational changes in EEG burst spectral power of the preterm infant with a normal follow-up at 2 years of age. Clin Neurophysiol. 123 (11), 2130-2138.

Oh, W.C., Lutzu, S., Castillo, P.E., Kwon, H.B., 2016. De novo synaptogenesis induced by GABA in the developing mouse cortex. Science. 353 (6303), 1037-1040.

Tau, G.Z., Peterson, B.S., 2010. Normal development of brain circuits. Neuropsychopharmacology. 35 (1), 147-168.

van Lier, H., Drinkenburg, W.H., van Eeten, Y.J., Coenen, A.M., 2004. Effects of diazepam and zolpidem on EEG beta frequencies are behavior-specific in rats. Neuropharmacology. 47 (2), 163-174.

DOI of original article: https://doi.org/10.1016/j.ijpsycho.2018.07.483

E-mail address: neuromediator@mail.ru (D. Chegodaev). 